\title{
Distribution and Metabolism of Dihomo- $\gamma$-linolenic Acid (DGLA, 20:3n-6) by Oral Supplementation in Rats
}

\author{
Rumi Umeda-Sawada, ${ }^{1,2}$ Yoko Fujiwara, ${ }^{1, \dagger}$ Ikuko Ushiyama, ${ }^{1}$ Satoe Sagawa, ${ }^{1}$ \\ Yasujiro Morimitsu, ${ }^{1}$ Hiroshi Kawashima, ${ }^{3}$ Yoshiko Ono, ${ }^{3}$ Yoshinobu Kiso, ${ }^{3}$ \\ Akiyo Matsumoto, ${ }^{4}$ and Yousuke Seyama ${ }^{1}$ \\ ${ }^{1}$ Department of Nutrition and Food Science, Ochanomizu University, Tokyo 112-8610, Japan \\ ${ }^{2}$ Division of Medical Devices, National Institute of Health Sciences, Tokyo 158-8501, Japan \\ ${ }^{3}$ Institute for Health Care Science, Suntory Ltd., Osaka 618-0001, Japan \\ ${ }^{4}$ Department of Clinical Dietetics \& Human Nutrition, Josai University, Saitama 350-0295, Japan
}

Received February 2, 2006; Accepted May 19, 2006; Online Publication, September 7, 2006

[doi:10.1271/bbb.60057]

We compared the dietary effects of dihomo- $\gamma$-linolenic acid (DGLA) contained in the DGLA oil produced by a fungus with $\gamma$-linolenic acid (GLA) on the fatty acid composition. Wistar rats were fed with three kinds of oil for two weeks as follows: (i) control group: corn oil; (ii) GLA group: borage oil; (iii) DGLA group: DGLA oil/ safflower oil $=55: 45$. The DGLA concentrations in the liver, serum, and brain of the DGLA group were higher than those of the GLA oil group. We also examined the dose effect of DGLA. The DGLA levels in the liver, serum, and brain significantly increased with increasing dosage of DGLA in the diet. DGLA administration significantly increased the ratio of $\mathrm{PGE}_{1} / \mathrm{PGE}_{2}$ in the rat plasma. The mechanism for GLA administration to improve atopic eczema is thought to involve an increase in the concentration of DGLA metabolized from GLA, so these results suggest that the dietary effect of DGLA would be more dominant than GLA.

Key words: dihomo- $\gamma$-linolenic acid (DGLA); arachidonic acid; delta 5 and delta 6 desaturase; rat

Dihomo- $\gamma$-linolenic acid (DGLA, 20:3n-6) is an intermediate metabolite of the $n-6$ series of polyunsaturated fatty acids (PUFA). DGLA is metabolized from linoleic acid (LA, 18:2n-6) via $\gamma$-linolenic acid (GLA, 18:3n-6) and further converted to arachidonic acid (AA, 20:4n-6). DGLA, AA and eicosapentaenoic acid (EPA, 20:5n-3) are precursors of eicosanoids, e.g. prostaglandins (PG) and thromboxanes (TX). DGLA is converted to the 1-series of PG. $\mathrm{PGE}_{1}$, the major PG from DGLA, has such physiological functions as anti-inflammatory $^{1-3)}$ and anti-platelet aggregation activities. ${ }^{4)}$ DGLA has also been reported to have anti-inflammatory, ${ }^{5)}$ antithrombotic, ${ }^{6}$ antihypertensive, ${ }^{7)}$ and anti-allergic actions. ${ }^{8)}$ GLA-containing oils such as evening primrose oil and borage oil are often used for the treatment of allergic symptoms, ${ }^{9,10)}$ atopic eczema, ${ }^{11)}$ uremic skin symptoms $^{12)}$ and premenstrual syndrome ${ }^{13-15)}$ in humans. Some of these physiological effects of GLA are thought to originate from its metabolites, DGLA and $\mathrm{PGE}_{1}$. Therefore, DGLA administration can be expected to be more effective than GLA administration. Several studies that DGLA ethyl ester were fed to rats and rabbits were published ${ }^{16-18)}$ in 1970'. However, the natural source of DGLA was not available and its general use for treatment has been limited. We have been able to get commercially produced DGLA oil in the form of triacylglycerol (TG) recently, produced by a $\Delta 5$ desaturase-defective mutant of the Mortierella alpina 1S-4 fungus. ${ }^{19)}$ We therefore reevaluate the dietary effect of DGLA in vivo in this present study.

We compared the dietary effects of DGLA with GLA on the fatty acid metabolism in rat tissues. We also examined the dietary effects of DGLA on the concentrations of $\mathrm{PGs}\left(\mathrm{PGE}_{1}\right.$ and $\left.\mathrm{PGE}_{2}\right)$ in rat plasma. We finally measured the mRNA levels of fatty acid $\Delta 5$ and $\Delta 6$ desaturases and two transcriptional factors, peroxisome proliferator-activated receptor $\alpha(\operatorname{PPAR} \alpha)$ and sterol regulatory element-binding protein-1 (SREBP-1), in rat liver.

\section{Materials and Methods}

Chemicals. The DGLA oil was prepared from a $\Delta 5$ desaturase-defective mutant of Mortierella alpina 1S-4 fungus, ${ }^{19)}$ and borage oil was obtained from Sigma

$\dagger$ To whom correspondence should be addressed. Fax: +81-3-5978-5751; E-mail: fujiwara.yoko@ocha.ac.jp

Abbreviations: AA, arachidonic acid; DGLA, dihomo- $\gamma$-linolenic acid; EPA, eicosapentaenoic acid; FXR, farnesoid X receptor; GLA, $\gamma$-linolenic acid; HNF $4 \alpha$, hepatocyte nuclear factor $4 \alpha$; PG, prostaglandins; PPAR $\alpha$, peroxisome proliferator-activated receptor $\alpha$; PUFA, polyunsaturated fatty acid; SREBP-1, sterol regulatory element-binding protein-1; TX, thromboxane 
(St. Louis, MO, USA). EPA ethyl esters (purity > 99\%) were obtained from Harima Chemicals (Ibaraki, Japan), and corn oil, high-LA safflower oil, and high-oleic-acid sunflower oil were provided by Showa Sangyo Co. (Chiba, Japan).

Animals and diets. All experiments were approved by the Animal Experimentation Ethics Committee of Ochanomizu University (Tokyo, Japan). Four-week-old male Wistar rats were purchased from Sankyo Lab. Service (Tokyo, Japan). The rats were initially fed on a commercial diet (CE-2, Nippon Clea Co., Tokyo, Japan) for a week.

Experiment 1. Weighing an average of $140 \mathrm{~g}$, the animals were then divided into three groups of seven animals each. They were housed individually in an airconditioned room at $23 \pm 1{ }^{\circ} \mathrm{C}$ with a 12-h light-dark cycle and were given the experimental diets $(20 \mathrm{~g} /$ day for 1-4 day; $30 \mathrm{~g} /$ day for 5-14 day) and water ad libitum for $2 \mathrm{wk}$. The basal diet prepared under standards given by the American Institute of Nutrition (AIN) ${ }^{20)}$ was purchased from Eisai Co. (Tokyo, Japan) and contained the following percentage of ingredients (weight basis): casein, 20; glucose, 25; sucrose, 25; corn starch, 15; filter paper, 5; AIN mineral mixture, 3.5; AIN vitamin mixture, 1 ; choline bitartrate, 0.2 ; and DLmethionine, 0.3 . The test diets were prepared by mixing $5 \%(\mathrm{w} / \mathrm{w})$ of each experimental oil mixture with the basal diet. Three kinds of oil were prepared: (i) control (CO) group, corn oil; (ii) GLA group, borage oil; (iii) DGLA group, DGLA oil/high LA safflower oil = 55:45. EPA ethyl esters (less than $1 \%$ of the dietary oils) were added to all three dietary oils to supply n-3 fatty acids. The fatty acid compositions of the three kinds of oil are shown in Table 1. The concentration of both GLA in the of oil of the GLA group and of DGLA in the oil of the DGLA group was adjusted to $c a$. $20 \%$. The concentration of LA in the GLA and DGLA groups was at the same level, while the concentration of total n-6 fatty acid was no different among the three groups (50-58\%).

Experiment 2. Weighing an average of $144 \mathrm{~g}$, the animals were then divided into three groups of seven

Table 1. Fatty Acid Composition of Dietary Oils ${ }^{\mathrm{a}}$

\begin{tabular}{lrrr}
\hline \hline & CO & GLA & DGLA \\
\hline $16: 0$ & 12.2 & 11.5 & 13.7 \\
$18: 0$ & 2.7 & 4.3 & 5.6 \\
$18: 1 n-9$ & 33.2 & 16.4 & 11.8 \\
$18: 2 n-6$ (LA) & 49.2 & 35.8 & 34.3 \\
$18: 3 n-6$ (GLA) & - & 21.1 & 1.3 \\
20:3n-6 (DGLA) & - & - & 23.1 \\
20:5n-3 (EPA) & 0.7 & 0.7 & 0.8 \\
\hline Total n-6 & 49.2 & 56.9 & 58.7 \\
\hline
\end{tabular}

${ }^{a}$ Values are expressed as weight percentages. CO, corn oil; GLA, $\gamma$-linolenic acid; DGLA, dihomo- $\gamma$-linolenic acid; LA, linoleic acid; EPA, eicosapentaenoic acid
Table 2. Fatty Acid Composition of Dietary Oils ${ }^{\mathrm{a}}$

\begin{tabular}{lccc}
\hline \hline & $0 \%$ & $10 \%$ & $20 \%$ \\
\hline $16: 0$ & 4.33 & 8.27 & 12.2 \\
$18: 0$ & 3.84 & 4.87 & 5.98 \\
$18: 1 n-9$ & 85.4 & 68.9 & 48.7 \\
$18: 2 n-6$ (LA) & 5.76 & 5.65 & 5.58 \\
$18: 3 n-6$ (GLA) & - & - & 1.10 \\
$18: 3 n-3$ (ALA) & - & - & 0.55 \\
$20: 3 n-6$ (DGLA) & - & 9.03 & 19.6 \\
$24: 0$ & - & 1.68 & 3.73 \\
\hline
\end{tabular}

${ }^{a}$ Values are expressed as weight percentages. See Table 1 for abbreviations.

animals each. They were housed individually in an airconditioned room at $23 \pm 1{ }^{\circ} \mathrm{C}$ with a 12-h light-dark cycle and were given the experimental diets $(20 \mathrm{~g} /$ day for 1-3 day; $30 \mathrm{~g} /$ day for 4-21 day) and water ad libitum for $3 \mathrm{wk}$. The basal diet used was the same as that in Experiment 1 . The test diets were prepared by mixing $5 \%(\mathrm{w} / \mathrm{w})$ for the experimental oil mixtures with the basal diet. Three kinds of oils were prepared: (i) DGLA 0\% group, high oleic acid sunflower oil (HOS); (ii) DGLA $10 \%$ group, DGLA oil $/ \mathrm{HOS}=1: 3$; (iii) DGLA $20 \%$ group, DGLA oil/HOS $=1: 1$. The fatty acid compositions of the experimental oils are shown in Table 2.

Lipid analyses. Lipids were extracted from the livers of the rats by the method of Folch et al. ${ }^{21)}$ As an internal standard, margaric acid (17:0) was added to the lipid extracts which were methylated by using HCL-methanol as described in our previous paper ${ }^{22}$ to measure the concentration of fatty acids in the tissues and serum. The fatty acid methyl esters were then measured by gasliquid chromatography (Perkin Elmer Auto System GC; Palo Alto, CA, USA) in a Rascot Sillar 5CP capillary column $(0.25 \mathrm{~mm} \times 50 \mathrm{~m}$; Nihon Chromato Works, Tokyo, Japan) as described previously. ${ }^{22)}$

Assesment of platlet aggregation. Platelet aggregation was measured with a whole blood aggregometer (WBA Model-4, MC Medical CO., Tokyo, Japan) by the screen filtration pressure method. ${ }^{23)}$ Briefly, blood was collected and incubated in saline with $16 \mu \mathrm{M}$ adenosine diphosphate (ADP) at $37^{\circ} \mathrm{C}$. Five minutes after the reaction had been started, the filter-unit syringe sequentially sucked in the blood samples. A pressure sensor was connected to the syringe, and the final platelet aggregation pressure was determined as the percentage pressure.

Determination of the plasma $P G E_{1}$ and $P G E_{2}$ levels. The $\mathrm{PGE}_{1}$ concentration in the rat plasma samples was determined by an enzyme-linked immunosorbent assay (ELISA) kit (R\&D Systems, Mineapolis, MN, USA). The $\mathrm{PGE}_{2}$ concentrations were also determined by ELISA (Cayman Chemical CO., Ann Arbor, MI). 
Table 3. Primers and Probe for Real-Time RT-PCR

\begin{tabular}{|c|c|c|c|c|c|}
\hline Gene name & $\begin{array}{l}\text { GenBank }^{\mathrm{TM}} \\
\text { accession } \\
\text { number }\end{array}$ & $\begin{array}{l}\text { Primer } \\
\text { orientation } \\
\text { or probe }\end{array}$ & Nucleotide sequence & $\begin{array}{l}\text { Starting } \\
\text { sequence } \\
\text { position }\end{array}$ & $\begin{array}{l}\text { Size for the } \\
\text { PCR } \\
\text { amplicon (bp) }\end{array}$ \\
\hline$\Delta 6$ desaturase & AF320509 & $\begin{array}{l}\text { Forward } \\
\text { Reverse }\end{array}$ & $\begin{array}{l}5^{\prime} \text {-GTTCTTCTTTCTCCTCCTGTCCC-3' } \\
5^{\prime} \text {-CATTGCCGAAGTACGAGAGGAT-3' }\end{array}$ & $\begin{array}{l}486 \\
565\end{array}$ & 79 \\
\hline$\Delta 5$ desaturase & AB021980 & $\begin{array}{l}\text { Forward } \\
\text { Reverse } \\
\text { Probe }\end{array}$ & $\begin{array}{l}\text { 5'-TGGCTCACTCTTTGGATCTTTG-3' } \\
\text { 5'-GCCTGAACTGTACTGAGCAGCA-3' } \\
\text { 5'-AACTTCCTTGGTGCCTTCACCCTCTGT-3' }\end{array}$ & $\begin{array}{l}448 \\
524 \\
471\end{array}$ & 76 \\
\hline $\operatorname{PPAR} \alpha$ & NM013196 & $\begin{array}{l}\text { Forward } \\
\text { Reverse }\end{array}$ & $\begin{array}{l}5^{\prime} \text {-AGCCAACGGCGTTGAAAA-3' } \\
5^{\prime} \text {-GGACATGCACTGGCAGCA-3' }\end{array}$ & $\begin{array}{l}1154 \\
1217\end{array}$ & 63 \\
\hline SREBP-1 & L16995 & $\begin{array}{l}\text { Forward } \\
\text { Reverse }\end{array}$ & $\begin{array}{l}\text { 5'-GGCTGGCCAATGGACTACTAGT-3' } \\
\text { 5'-CAGCTTGTTTGCGATGTCTCC-3' }^{\prime}\end{array}$ & $\begin{array}{l}1589 \\
1708\end{array}$ & 119 \\
\hline
\end{tabular}

Table 4. Fatty Acid Composition of the Liver of Rats

\begin{tabular}{|c|c|c|c|}
\hline & $\mathrm{CO}$ & GLA & DGLA \\
\hline & & & $(\mu \mathrm{mol} / \mathrm{g}$ of tissue $)$ \\
\hline $16: 0$ & $49.4 \pm 10.40^{\mathrm{a}, \mathrm{b}}$ & $60.4 \pm 13.00^{\mathrm{a}}$ & $438.8 \pm 8.34^{\mathrm{b}}$ \\
\hline $16: 1$ & $5.34 \pm 2.68$ & $5.71 \pm 1.20$ & $4.34 \pm 1.24$ \\
\hline 18:0 & $27.7 \pm 0.92$ & $27.9 \pm 1.00$ & $27.1 \pm 0.70$ \\
\hline $18: 1 \mathrm{n}-9$ & $40 \pm 12.30^{\mathrm{a}}$ & $41.5 \pm 11.10^{\mathrm{a}}$ & $22.9 \pm 5.67^{\mathrm{b}}$ \\
\hline $18: 2 n-6$ & $42.7 \pm 8.43^{\mathrm{a}}$ & $45.3 \pm 11.80^{\mathrm{a}}$ & $28.6 \pm 6.12^{\mathrm{b}}$ \\
\hline $18: 3(n-6)$ & $1.09 \pm 0.27^{\mathrm{a}}$ & $6.7 \pm 1.63^{\mathrm{b}}$ & $1.24 \pm 0.30^{\mathrm{a}}$ \\
\hline $18: 3(n-3)$ & $0.51 \pm 0.17$ & $0.41 \pm 0.32$ & $0.38 \pm 0.18$ \\
\hline $20: 3(n-6)$ & $0.49 \pm 0.05^{\mathrm{a}}$ & $2.25 \pm 0.66^{\mathrm{b}}$ & $8.72 \pm 2.46^{\mathrm{c}}$ \\
\hline $20: 4(n-6)$ & $34 \pm 1.24^{\mathrm{a}}$ & $53.3 \pm 6.93^{\mathrm{b}}$ & $54.9 \pm 8.00^{\mathrm{b}}$ \\
\hline $20: 5(n-3)$ & $0.82 \pm 0.22^{\mathrm{a}}$ & $1.21 \pm 0.26^{\mathrm{b}}$ & $1.03 \pm 0.29^{\mathrm{ab}}$ \\
\hline $22: 4(n-6$ & $0.58 \pm 0.28^{\mathrm{a}}$ & $3.05 \pm 1.25^{\mathrm{b}}$ & $1.87 \pm 0.77^{\mathrm{c}}$ \\
\hline $22: 5(n-6)$ & $1.02 \pm 0.54^{\mathrm{a}}$ & $4.19 \pm 1.34^{\mathrm{b}}$ & $2.97 \pm 0.66^{\mathrm{c}}$ \\
\hline $22: 5(n-3)$ & $0.24 \pm 0.41^{\mathrm{a}}$ & $0.99 \pm 0.34^{\mathrm{b}}$ & $0.68 \pm 0.24^{\mathrm{ab}}$ \\
\hline $22: 6(n-3)$ & $9.5 \pm 0.88^{\mathrm{a}}$ & $8.28 \pm 0.86^{b}$ & $7.41 \pm 0.59^{c}$ \\
\hline \multicolumn{4}{|l|}{ Desaturation index } \\
\hline $\mathrm{LA} /(\mathrm{GLA}+\mathrm{DGLA}+\mathrm{AA})$ & $0.553 \pm 0.867$ & $0.449 \pm 0.609$ & $0.310 \pm 0.369$ \\
\hline DGLA/AA & $0.014 \pm 0.040^{\mathrm{a}}$ & $0.042 \pm 0.095^{\mathrm{b}}$ & $0.159 \pm 0.308^{\mathrm{c}}$ \\
\hline
\end{tabular}

Each result is expressed as $\mathrm{mmol} / \mathrm{g}$ of tissue and is the mean $\pm \mathrm{SD}$.

Values with different superscript letters show significant difference $(\mathrm{P}<0.05)$.

Total RNA preparation and real-time quantitative $R T$ $P C R$. Total RNA was isolated from the rat liver samples by the acid-phenol guanidinium method. Real-time quantitative RT-PCR was performed with a GeneAmp 5700 sequence detection system (Applied Biosystems). Real time RT-PCR was performed with specific primers and probes corresponding to different genes (Table 3). A SYBR-green quantitative PCR assay was performed to detect $\Delta 6$ desaturase, PPAR $\alpha$, and SREBP- 1 mRNAs, while a fluorogenic probe and the primers were used with PCR for $\Delta 5$ desaturase mRNA detection. The expression level of glyceraldehyde-3-phosphate dehydrogenase (GAPDH) was determined by using a Taq Man Rodent Control Reagent kit (Applied Biosystems) and used for normalization of the data.

Statistical analysis. Each result is shown as the mean \pm SD. The significance of the difference in mean values was evaluated by Student's t-test.

\section{Results}

\section{Experiment 1}

Experiment 1 was a comparative study on the dietary effects of DGLA and GLA on the fatty acid metabolism in the rat liver, serum, and brain.

Growth parameters and tissue weights

No significant differences in the food intake and body weight gain were apparent among the animal groups (data are not shown). We conclude that the administration of DGLA oil had no influence on the growth of the rats.

Fatty acid concentration in the rat tissues

The effect of the dietary oils on fatty acid concentration in rat liver is shown in Table 4. The DGLA (20:3n-6) concentration in the GLA group was significantly higher than that in the $\mathrm{CO}$ group. The DGLA concentration in the DGLA group was also significantly higher than that in the CO and GLA groups. The AA 
Table 5. Fatty Acid Composition of the Serum of Rats

\begin{tabular}{|c|c|c|c|}
\hline & $\mathrm{CO}$ & GLA & DGLA \\
\hline & & & $(\mu \mathrm{mol} / \mathrm{g}$ of tissue $)$ \\
\hline $16: 0$ & $1.25 \pm 0.19^{\mathrm{a}}$ & $1.38 \pm 0.15^{\mathrm{ab}}$ & $1.55 \pm 0.16^{\mathrm{b}}$ \\
\hline $16: 1$ & $0.14 \pm 0.04^{\mathrm{ab}}$ & $0.14 \pm 0.02^{\mathrm{ab}}$ & $0.17 \pm 0.03^{\mathrm{b}}$ \\
\hline $18: 0$ & $0.73 \pm 0.06^{\mathrm{a}}$ & $0.83 \pm 0.12^{\mathrm{ab}}$ & $0.94 \pm 0.11^{\mathrm{b}}$ \\
\hline $18: 1 \mathrm{n}-9$ & $0.73 \pm 0.23$ & $0.68 \pm 0.12$ & $0.69 \pm 0.12$ \\
\hline $18: 2 n-6$ & $0.97 \pm 0.23$ & $0.82 \pm 0.14$ & $0.85 \pm 0.16$ \\
\hline $18: 3(n-6)$ & $0.04 \pm 0.01^{\mathrm{a}}$ & $0.19 \pm 0.20^{\mathrm{b}}$ & $0.06 \pm 0.02^{c}$ \\
\hline $18: 3(n-3)$ & $0.01 \pm 0.01^{\mathrm{ab}}$ & $0.01 \pm 0.01^{\mathrm{ab}}$ & $0.01 \pm 0.01^{\mathrm{b}}$ \\
\hline $20: 3(n-6)$ & $0.01 \pm 0.00^{\mathrm{a}}$ & $0.03 \pm 0.01^{\mathrm{b}}$ & $0.27 \pm 0.05^{\mathrm{c}}$ \\
\hline $20: 4(n-6)$ & $1.76 \pm 0.10^{\mathrm{a}}$ & $2.25 \pm 0.34^{\mathrm{b}}$ & $2.75 \pm 0.37^{\mathrm{c}}$ \\
\hline $20: 5(n-3)$ & $0.03 \pm 0.01$ & $0.03 \pm 0.01$ & $0.04 \pm 0.01$ \\
\hline $22: 4(n-6$ & $0.01 \pm 0.01^{\mathrm{a}}$ & $0.04 \pm 0.00^{\mathrm{b}}$ & $0.04 \pm 0.01^{\mathrm{b}}$ \\
\hline $22: 5(n-6)$ & $0.03 \pm 0.01^{\mathrm{a}}$ & $0.08 \pm 0.02^{\mathrm{b}}$ & $0.08 \pm 0.02^{\mathrm{b}}$ \\
\hline $22: 5(n-3)$ & $0.05 \pm 0.01^{\mathrm{a}}$ & $0.15 \pm 0.01^{\mathrm{b}}$ & $0.04 \pm 0.02^{\mathrm{a}}$ \\
\hline $22: 6(n-3)$ & $0.18 \pm 0.03$ & $0.15 \pm 0.02$ & $0.17 \pm 0.02$ \\
\hline \multicolumn{4}{|l|}{ Desaturation index } \\
\hline $\mathrm{LA} /(\mathrm{GLA}+\mathrm{DGLA}+\mathrm{AA})$ & $0.35 \pm 0.70$ & $0.26 \pm 0.29$ & $0.22 \pm 0.28$ \\
\hline DGLA/AA & $0.006 \pm 0.001^{\mathrm{a}}$ & $0.013 \pm 0.029^{b}$ & $0.098 \pm 0.135^{\mathrm{c}}$ \\
\hline
\end{tabular}

Each result is expressed as $\mathrm{mmol} / \mathrm{g}$ of tissue and is the mean $\pm \mathrm{SD}$.

Values with different superscript letters show significant difference $(\mathrm{P}<0.05)$.

Table 6. Fatty Acid Composition of the Brain of Rats

\begin{tabular}{|c|c|c|c|}
\hline & $\mathrm{CO}$ & GLA & DGLA \\
\hline & & & ( $\mu \mathrm{mol} / \mathrm{g}$ of tissue) \\
\hline $16: 0$ & $23.3 \pm 2.00$ & $22.6 \pm 0.75$ & $22.8 \pm 1.14$ \\
\hline $16: 1$ & $0.39 \pm 0.04$ & $0.37 \pm 0.05$ & $0.39 \pm 0.04$ \\
\hline 18:0 & $23.4 \pm 1.44$ & $23.1 \pm 0.66$ & $23 \pm 0.94$ \\
\hline $18: 1 \mathrm{n}-9$ & $14.8 \pm 0.84$ & $14.9 \pm 0.63$ & $14.9 \pm 0.80$ \\
\hline $18: 2 n-6$ & $0.69 \pm 0.06$ & $0.51 \pm 0.03^{\mathrm{b}}$ & $0.51 \pm 0.04^{\mathrm{b}}$ \\
\hline $18: 3(n-6)$ & ND & ND & ND \\
\hline $18: 3(n-3)$ & ND & ND & ND \\
\hline $20: 3(n-6)$ & $0.27 \pm 0.12^{\mathrm{a}}$ & $0.51 \pm 0.03^{\mathrm{b}}$ & $0.61 \pm 0.09^{c}$ \\
\hline $20: 4(n-6)$ & $8.79 \pm 0.67^{\mathrm{a}}$ & $9.59 \pm 0.20^{\mathrm{b}}$ & $9.43 \pm 0.55^{\mathrm{ab}}$ \\
\hline $20: 5(n-3)$ & ND & ND & ND \\
\hline $22: 4(n-6$ & $2.01 \pm 0.23$ & $2.2 \pm 0.07$ & $2.23 \pm 0.19$ \\
\hline $22: 5(n-6)$ & $0.31 \pm 0.14^{\mathrm{a}}$ & $0.54 \pm 0.06^{\mathrm{b}}$ & $0.51 \pm 0.08^{\mathrm{b}}$ \\
\hline $22: 5(n-3)$ & $1.17 \pm 0.18$ & $1.14 \pm 0.12$ & $1.11 \pm 0.16$ \\
\hline $22: 6(n-3)$ & $8.96 \pm 0.84$ & $9.49 \pm 0.31$ & $9.4 \pm 0.81$ \\
\hline \multicolumn{4}{|l|}{ Deaturation index } \\
\hline LA/(GLA+DGLA+AA) & $0.0708 \pm 0.0706$ & $0.0481 \pm 0.1154$ & $0.0483 \pm 0.0588$ \\
\hline DGLA/AA & $0.0307 \pm 0.1791^{\mathrm{a}}$ & $0.0532 \pm 0.1500^{\mathrm{b}}$ & $0.0647 \pm 0.1636^{\mathrm{c}}$ \\
\hline
\end{tabular}

Each result is expressed as $\mathrm{mmol} / \mathrm{g}$ of tissue and is the mean $\pm \mathrm{SD}$.

Values with different superscript letters show significant difference $(\mathrm{P}<0.05)$.

(20:4n-6) concentrations in the GLA and DGLA groups were significantly higher than that in the $\mathrm{CO}$ group. No significant difference was apparent observed in the AA $(20: 4 n-6)$ concentration between the GLA and DGLA groups. Table 5 shows the effect of dietary oils on the fatty acid concentration in rat serum. The DGLA (20:3n-6) concentration in the GLA group was also significantly higher than that in the CO group, and the concentration of DGLA in the DGLA group was also significantly higher than that in the $\mathrm{CO}$ and GLA groups. The AA (20:4n-6) concentration was highest in the order of DGLA group > GLA group > CO group, similar to the DGLA concentration. Table 6 shows the effect of dietary oils on the fatty acid concentration in the rat brain. Similar to the liver and serum, the DGLA (20:3n-6) concentration in the GLA group was significantly higher than that in the $\mathrm{CO}$ group, while the DGLA concentration in the DGLA group was significantly higher than that in the CO and GLA groups. However, the quantitative difference among the three groups in the brain was much less than that in the liver or serum. The AA (20:4n-6) concentration was not much different among three groups. The DGLA/AA ratio in these tissues when treated with the DGLA diet was higher than that in the control and GLA groups. 

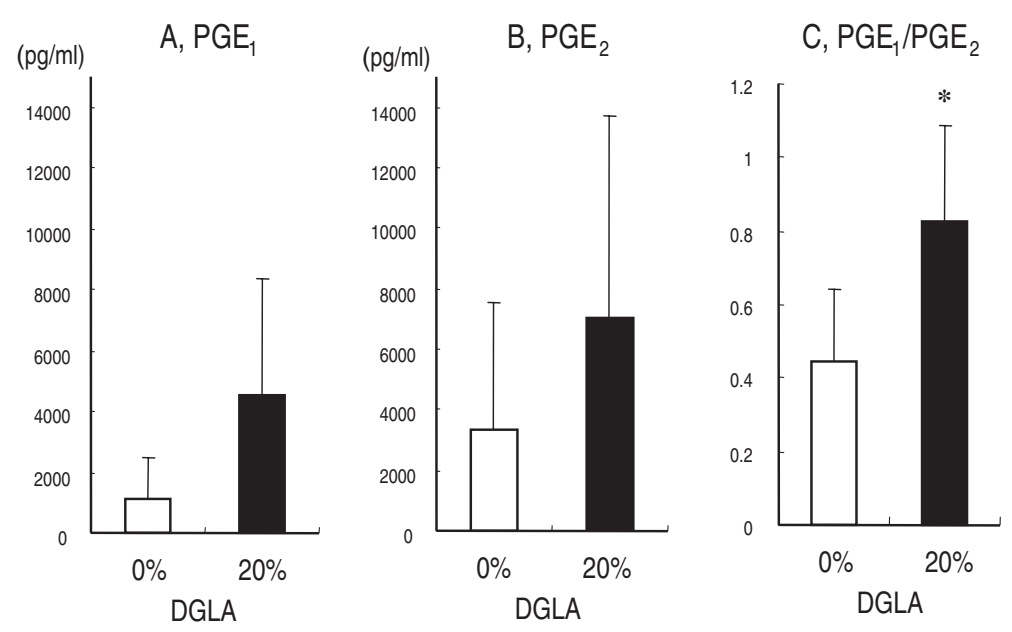

Fig. 1. Effect of DGLA on Platelet Aggregation.

Blood samples were collected from rats. The platelet aggregation rate was determined by using WBA as described in the Materials and Methods section. ${ }^{*}$ significant difference $v$. control $(\mathrm{P}<0.05)$.

\section{Platelet aggregation}

Figure 1 shows the effect of DGLA on platelet aggregation measured by the WBA method, involving a new type of aggregometer. This method has good reproducibility and easy handling with a small sample volume. In Fig. 1, a low pressure rate means low aggregation ability. DGLA feeding caused a significant decrease in platelet aggregation compared to the control diet. DGLA was more efficient than the GLA diet in this effect.

\section{Experiment 2}

We investigated in experiment 2 , the dose dependence of dietary DGLA on the fatty acid metabolism in the liver, serum, and brain of rats. The dietary effects of DGLA on the $\mathrm{PGE}_{1}$ and $\mathrm{PGE}_{2}$ concentrations in rat plasma and on the mRNA expression of $\Delta 5$ and $\Delta 6$ desaturase, PPAR $\alpha$, and SREBP-1 in rat liver were also investigated.

Fatty acid concentrations in rat tissues

The fatty acid concentration in rat liver is shown in Fig. 2A. The DGLA (20:3n-6) concentration in the liver was significantly increased with increasing dietary DGLA. Dietary DGLA also significantly increased the AA (20:4n-6) concentration in the rat liver, although no significant difference was apparent in the AA concentration between the DGLA $10 \%$ and $20 \%$ groups. Similar to the concentration of DGLA (20:3n-6), those of 22:4n-6 and 22:5n-6 were significantly increased with increasing dietary DGLA. On the contrary, the DHA (22:6n-3) concentration was significantly decreased with increasing dietary DGLA. The fatty acid concentration in rat serum is shown in Fig. 2B. The DGLA (20:3n-6) concentration in the serum was also significantly increased with increasing dietary DGLA, as was the concentration of 22:5n-6. Dietary DGLA (20:3n-6) also significantly increased the AA (20:4n-6) concentration in rat serum, although no significant difference was apparent in AA concentration between the DGLA 10\% and $20 \%$ groups. On the contrary, the DHA (22:6n-3) concentration was significantly decreased by dietary DGLA. Oral administration of DGLA had no effect on the concentrations of DGLA (20:3n-6), AA (20:4n-6), and $22: 4 n-6$ in the rat brain, similar to the results in experiment 1 (data are not shown).

Concentrations of $P G E_{1}$ and $P G E_{2}$ in rat plasma

The effect of dietary DGLA on the concentrations of $\mathrm{PGE}_{1}$ and $\mathrm{PGE}_{2}$ in rat plasma is shown in Fig. 3 for the DGLA $0 \%$ and $20 \%$ groups. Dietary DGLA increased the $\mathrm{PGE}_{1}$ concentration to a level about four times higher than that without DGLA administration (Fig. 3A). On the other hand, dietary DGLA increased the $\mathrm{PGE}_{2}$ concentration to a level less than twice that without DGLA (Fig. 3B). Therefore, the ratio of $\mathrm{PGE}_{1} /$ $\mathrm{PGE}_{2}$ was significantly increased by dietary DGLA (Fig. 3C).

$m R N A$ expression of $\triangle 5$ and $\triangle 6$ desaturase, PPAR $\alpha$, and SREBP-1

The mRNA expression of $\Delta 5$ and $\Delta 6$ desaturase, PPAR $\alpha$, and SREBP-1 in the DGLA $0 \%$ and $20 \%$ groups was investigated. The significant decreasing effect of dietary DGLA on the mRNA expression of $\Delta 5$ and $\Delta 6$ desaturase in rat liver is shown in Fig. 4. Figure 5 shows the significant decreasing effect of dietary DGLA on the mRNA expression of PPAR $\alpha$ in rat liver, and the tendency for the down regulation of SREBP-1 mRNA expression by dietary DGLA.

\section{Discussion}

We investigated in the present study the effect of dietary DGLA on the fatty acid metabolism in vivo by using DGLA in TG form produced by a fungus. The effect of supplementation of ethyl DGLA on the lipid metabolism in rat tissues ${ }^{16)}$ has been reported. Oelz et al. have also investigated the effect of feeding ethyl DGLA 

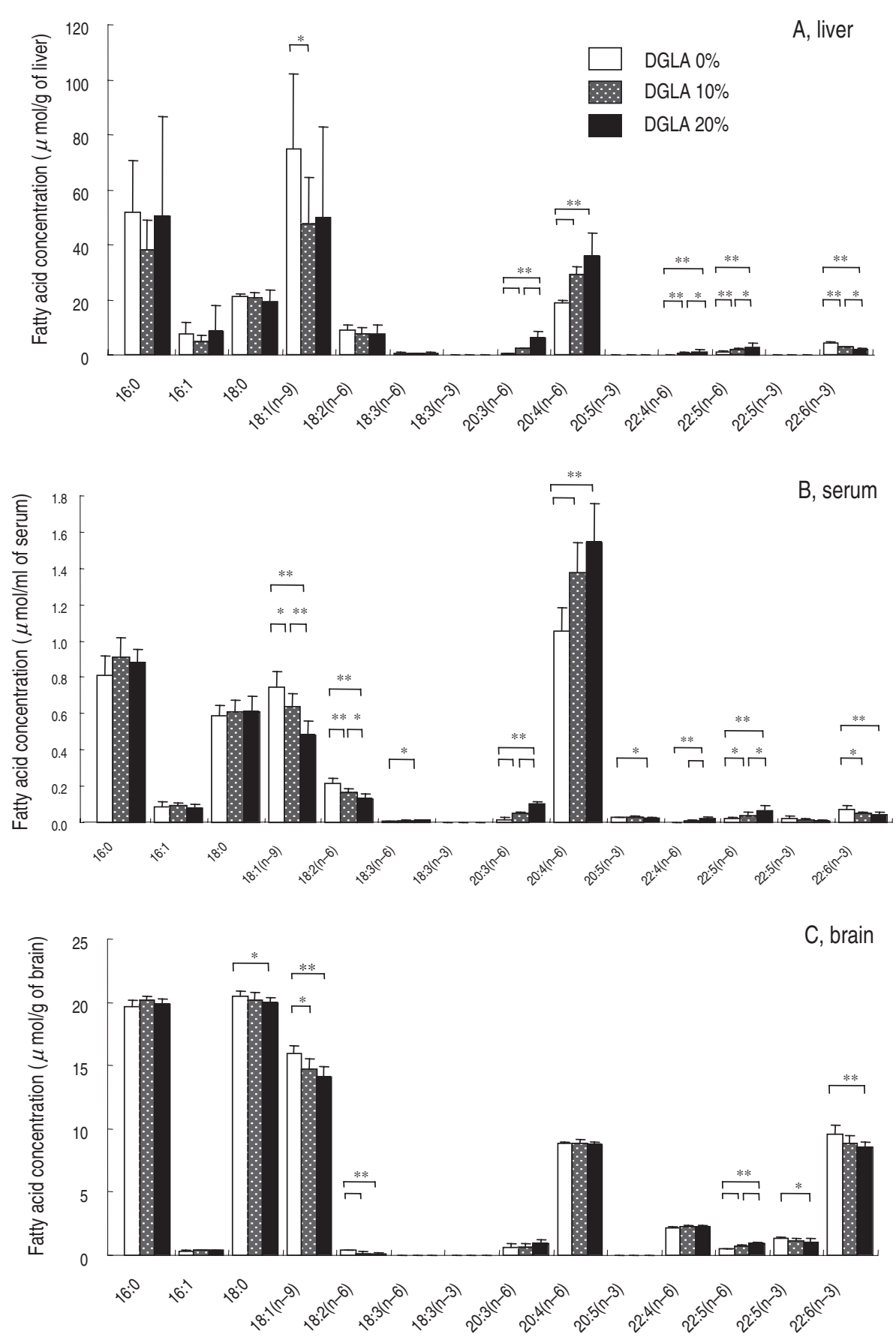

Fig. 2. Dose Effect of Dietary DGLA on the Fatty Acid Concentration in Rat Tissues.

Each value is the mean \pm SD of seven determinations made on separate animals. Bars with asterisks show significant difference at $p<0.05$ and with double asterisks are significantly different at $\mathrm{p}<0.005$. (A) liver; (B) serum; (C) brain. See Table 1 for abbreviations.

to rabbits on $\mathrm{PG}$ biosynthesis and platelet aggregations, ${ }^{17)}$ while Knapp et al. have demonstrated that dietary ethyl DGLA increased PGE $_{1}$ production in the renal papilla of rabbits. ${ }^{18)}$ As differences in the digestion and lymphatic transport of fatty acids between those given in the form of an ethyl ester and TG have already been shown in rats, ${ }^{24)}$ we tried to confirm the dietary effect of DGLA in TG form in vivo.

In experiment 1 , we compared the dietary effects of DGLA with those of GLA on the fatty acid composition of rat tissues. Dietary DGLA significantly increased the DGLA concentration in the liver, serum, and brain compared with dietary GLA (Tables 4, 5 and 6). These results suggested that DGLA administration was more effective for increasing the DGLA concentration in tissues than GLA administration. It is therefore suggested that DGLA administration was more effective for anti-platelet aggregation than GLA as shown in Fig. 1. The alteration in the brain fatty acid composition was smaller than that in the liver and serum, suggesting that 

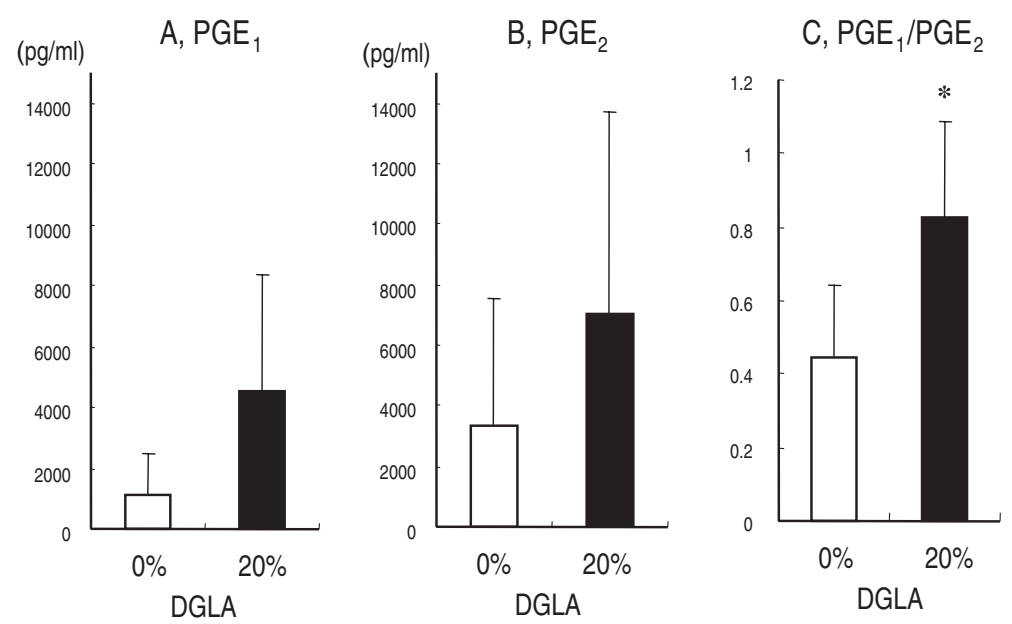

Fig. 3. Effect of Dietary DGLA on the Concentration of $\mathrm{PGE}_{1}$ and $\mathrm{PGE}_{2}$ in Rat Plasma.

Each value is the mean \pm SD of seven determinations made on separate animals. Bars with asterisks show significantly difference from the DGLA 0\% group (p < 0.05). (A) $\mathrm{PGE}_{1}$; (B) $\mathrm{PGE}_{2}$; (C) $\mathrm{PGE}_{1} / \mathrm{PGE}_{2}$. See Table 1 for abbreviations.
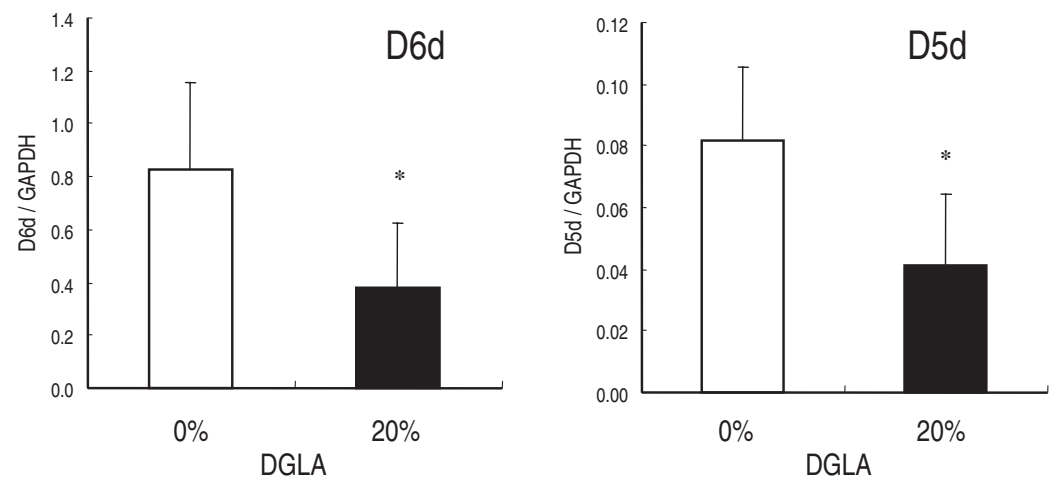

Fig. 4. Effect of Dietary DGLA on the mRNA Expression of $\Delta 6$ (D6d) and $\Delta 5$ (D5d) Desaturase in Rat Liver.

Each value is the mean $\pm \mathrm{SD}$ of seven determinations made on separate animals. Bars with asterisks show significant difference from the DGLA $0 \%$ group $(\mathrm{p}<0.05)$. See Table 1 for abbreviations.
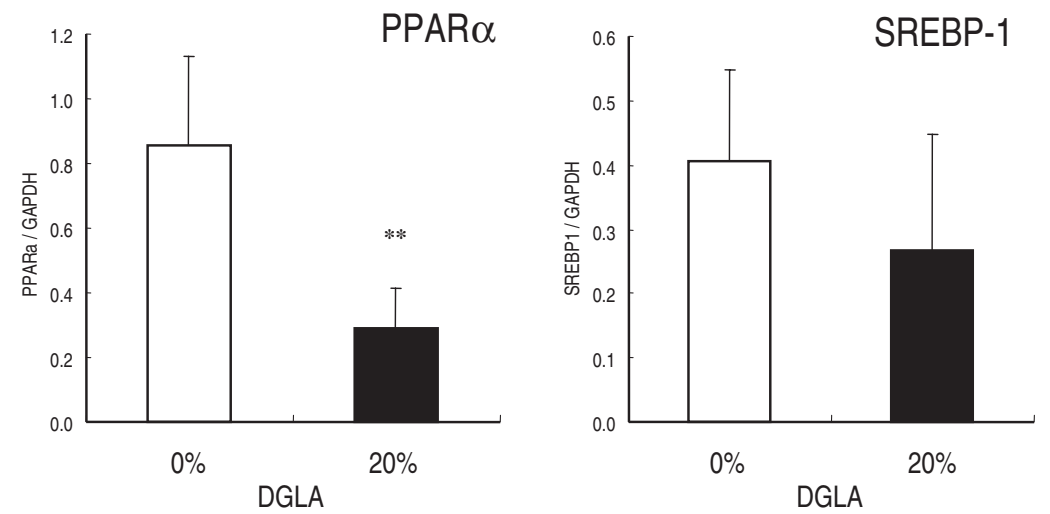

Fig. 5. Effect of Dietary DGLA on the mRNA Expression of PPAR $\alpha$ and SREBP-1 in Rat Liver.

Each value is shown the mean $\pm \mathrm{SD}$ of seven determinations made on separate animals. Bars with double asterisks show significant difference from the DGLA 0\% group $(\mathrm{p}<0.005)$. See Table 1 for abbreviations.

the method and rate of DGLA incorporation into each tissue were different. In experiment 2, the DGLA concentration in the liver and serum was with increasing level of dietary DGLA (Figs. 2A and B). However there was no significant difference between the DGLA $10 \%$ and $20 \%$ groups in the AA concentration (Figs. 2A and 
B). On the contrary, the concentrations of $22: 4 n-6$ and 22:5n-6 were increased with increasing dietary DGLA (Fig. 2). These results suggest that the AA concentration in the tissues was maintained constant in vivo. And oral administration of DGLA-containing oil seemed not to cause any large excess of AA concentration in vivo. The decreased DHA concentration in rat tissues by administering DGLA might have been accompanied by the increase in 22:5n-6.

AA is the precursor of PG of the 2-series such as $\mathrm{PGE}_{2}$, leukotriene (LT) $\mathrm{B}_{4}, \mathrm{LTC}_{4}$, and $\mathrm{LTD}_{4} . \mathrm{PGE}_{2}$ is known as a mediator of inflammation. ${ }^{25-27)}$ It has been reported that there was a correlation between an increased $\mathrm{PGE}_{2}$ concentration and the risk of cancer development. ${ }^{28-31)}$ On the other hand, $\mathrm{PGE}_{1}$ converted from DGLA has anti-inflammatory ${ }^{32-34)}$ and anti-platelet aggregation activities. ${ }^{4)}$ It has been indicated that DGLA and $\mathrm{PGE}_{1}$ inhibited the synthesis of pro-inflammatory mediators such as $\mathrm{LTB}_{4}, \mathrm{LTC}_{4}$, and $\mathrm{LTD}_{4} \cdot{ }^{35)}$ The present study has shown that dietary DGLA significantly increased the ratio of $\mathrm{PGE}_{1} / \mathrm{PGE}_{2}$ in rat plasma (Fig. 3C). Knapp et al. have also demonstrated that dietary ethyl DGLA increased $\mathrm{PGE}_{1}$ production in vitro. ${ }^{18)}$ It was considered that the increase in $\mathrm{PGE}_{1} /$ $\mathrm{PGE}_{2}$ ratio was accompanied by an increase in DGLA/ $\mathrm{AA}$ in rat tissues. Although the cellular synthesis of $\mathrm{PGE}_{1}$ and $\mathrm{PGE}_{2}$ by adding GLA, DGLA, or $\mathrm{AA}^{36)}$ has been reported, we have demonstrated here the increase of $\mathrm{PGE}_{1} / \mathrm{PGE}_{2}$ ratio in vivo by administering DGLA in TG form. Therefore, dietary DGLA is expected to demonstrate anti-inflammatory and anti-platelet aggregation activities.

We also investigated the dietary effects of DGLA on the mRNA levels of essential fatty acid desaturases. We measured the mRNA expression of $\Delta 6$ desaturase, which catalyzes the conversion from LA (18:2) to GLA (n-6) and from $\alpha$-linolenic acid (18:3) to 18:4 (n-3), and of $\Delta 5$ desaturase which catalyzes the conversion from DGLA to AA (n-6) and from 20:4 to EPA (n-3). $\Delta 6$ desaturase is the first and rate-limiting enzyme of PUFA metabolism, and $\Delta 5$ desaturase plays an important role in the metabolism of eicosanoid precursors such as DGLA, AA, and EPA. Dietary DGLA significantly reduced the mRNA expression of both $\Delta 6$ and $\Delta 5$ desaturases (Fig. 4). Since it has been reported that both $\Delta 6$ and $\Delta 5$ desaturase expression was regulated by SREBP-1 and PPAR $\alpha,{ }^{37)}$ we also measured the hepatic mRNA expression of SREBP-1 and PPAR $\alpha$. DGLA administration reduced the mRNA expression of those (Fig. 5). Tang et al. have reported that dietary safflower oil and fish oil suppressed the hepatic expression of $\Delta 6$ and $\Delta 5$ desaturases. ${ }^{38)}$ They also indicated that the $\operatorname{PPAR} \alpha$ activator significantly enhanced the transcription of hepatic $\Delta 6$ and $\Delta 5$ desaturases. The human $\Delta 6$ desaturase promoter has the ability to bind heterodimer PPAR $\alpha$-retinoic acid receptor X (RXR) $\alpha .{ }^{38)}$ Moreover, DHA has the role of an agonist of $\operatorname{RXR} \alpha$, but not AA. ${ }^{39,40)}$ While PUFA is well known to suppress the
mRNA of SREBP, ${ }^{41-44)}$ it has not been much discussed whether PUFA would affect the expression of PPAR itself, and not its activation. Transcriptional regulation of PPAR $\alpha$ gene expression is different between humans and rodents. Whereas hPPAR $\alpha$ is regulated by hepatocyte nuclear factor $4 \alpha(\mathrm{HNF} 4 \alpha)^{45)}$ and bile acid via the farnesoid X receptor (FXR), ${ }^{46}$ rodent PPAR $\alpha$ is regulated by glucocortidoids. ${ }^{47)}$ Mouse PPAR $\alpha$ transcription is not stimulated by bile acids. ${ }^{46)}$ However, a study using HNF $4 \alpha$-deficient mice has demonstrated the significantly lower PPAR $\alpha$ mRNA level compared than that in wild-type mice. ${ }^{48)}$ It also showed that PPAR $\alpha$ expression was regulated by $\mathrm{HNF} 4 \alpha$ in mice. On the other hand, polyunsaturated fatty acyl coenzyme A has been reported to suppress the glucose-6-phosphatase promoter activity by inhibiting the binding of $\mathrm{HNF} 4 \alpha$ to its cognate site. ${ }^{49}$ Although we do not know why the DGLA treatment decreased the PPAR $\alpha$ mRNA level in our results, PUFA might be involved not only in the activation, but also in the PPAR $\alpha$ level via $\mathrm{HNF} 4 \alpha$. We did not examine the PPAR activation by DGLA; however, our results in this study suggest that DGLA suppressed the hepatic mRNA expression of $\Delta 6$ and $\Delta 5$ desaturases caused by the down-regulation of both SREBP-1 and PPAR $\alpha$. Although it is not clear how dietary GLA and DGLA controled the mRNA levels of D5D and D6D, the decreased D5D mRNA level in the DGLA group could be explained by the fact that the AA concentration in tissues did not increase much, even when a high dose of DGLA was given.

In conclusion, the present study was demonstrated that DGLA administration was more effective for increasing the DGLA concentration within the body than a GLA administration. Furthermore, dietary DGLA increased not only the DGLA concentration, but also the $\mathrm{PGE}_{1}$ concentration and then the ratio of $\mathrm{PGE}_{1} /$ $\mathrm{PGE}_{2}$ in vivo. Consequently, dietary DGLA is expected to demonstrate anti-inflammatory and anti-platelet aggregation effects. It was also found that a DGLA intake suppressed the hepatic mRNA expression of fatty acid desaturases by down-regulating of SREBP-1 and $\operatorname{PPAR} \alpha$ mRNA.

In spite of the difference between TG and ethyl esters in digestion, our results shown here are similar to those of previous studies using DGLA in the ethyl ester form. ${ }^{16-18)}$ Therefore, DGLA oil produced by a mutant fungus is expected to be a useful and popular method for providing DGLA.

\section{Acknowledgment}

This work was supported in part by the New Energy and Industrial Technology Development Organization.

\section{References}

1) Zurier, R. B., and Quagliate, F., Effect of prostaglandin E1 on adjuvant arthritis. Nature, 234, 304-305 (1971). 
2) Zurier, R. B., Sayadoffm, D. M., Torreym, S. B., and Rothfield, N. F., Prostaglandin E treatment in NZB/ NZW mice. Arthritis Rheum., 20, 723-728 (1977).

3) Zurier, R. B., Prostaglandins, immune responses, and murine lupus. Arthritis Rheum., 25, 804-809 (1982).

4) Kloeze, J., Relationship between chemical structure and platelet-aggregation activity of prostaglandins. Biochim. Biophys. Acta, 187, 285-292 (1969).

5) Nakamura, N., Hamazaki, T., Taki, H., Yamazaki, K., and Kobayashi, M., Intravenous infusion of tridihomogamma-linolenoyl-glycerol reduces leukotriene B4 production in the rat and rabbit. Clin. Sci. (Lond), 84, 511516 (1993).

6) Smith, D. L., Willis, A. L., Nguyen, N., Conner, D., Zahedi, S., and Fulks, J., Eskimo plasma constituents, dihomo-gamma-linolenic acid, eicosapentaenoic acid and docosahexaenoic acid, inhibit the release of atherogenic mitogens. Lipids, 24, 70-75 (1989).

7) Hassall, C. H., and Kirtland, S. J., Dihomo-gammalinolenic acid reverses hypertension induced in rats by diets rich in saturated fat. Lipids, 19, 699-703 (1984).

8) Taki, H., Nakamura, N., Hamazaki, T., and Kobayashi, M., Intravenous injection of tridihomo-gamma-linolenoyl-glycerol into mice and its effects on delayed-type hypersensitivity. Lipids, 28, 873-876 (1993).

9) Wright, S., and Burton, J. L., Oral evening-primroseseed oil improves atopic eczema. Lancet, 2, 1120-1122 (1982).

10) Schalin-Karrila, M., Mattila, L., Jansen, C. T., and Uotila, P., Evening primrose oil in the treatment of atopic eczema: effect on clinical status, plasma phospholipid fatty acids and circulating blood prostaglandins. Br. J. Dermatol., 117, 11-19 (1987).

11) Henz, B. M., Jablonska, S., van de Kerkhof, P. C., Stingl, G., Blaszczyk, M., Vandervalk, P. G., Veenhuizen, R., Muggli, R., and Raederstorff, D., Double-blind, multicentre analysis of the efficacy of borage oil in patients with atopic eczema. Br. J. Dermatol., 140, 685-688 (1999).

12) Yoshimoto-Furuie, K., Yoshimoto, K., Tanaka, T., Saima, S., Kikuchi, Y., Shay, J., Horrobin, D. F., and Echizen, H., Effects of oral supplementation with evening primrose oil for six weeks on plasma essential fatty acids and uremic skin symptoms in hemodialysis patients. Nephron, 81, 151-159 (1999).

13) Dickerson, L. M., Mazyck, P. J., and Hunter, M. H., Premenstrual syndrome. Am. Fam. Physician, 67, 17431752 (2003).

14) Horrobin, D. F., The role of essential fatty acids and prostaglandins in the premenstrual syndrome. J. Reprod. Med., 28, 465-468 (1983).

15) Horrobin, D. F., Evening primrose oil and premenstrual syndrome. Med. J. Aust., 153, 630-631 (1990).

16) Danon, A., Heimberg, M., and Oates, J. A., Enrichment of rat tissue lipids with fatty acids that are prostaglandin precursors. Biochim. Biophys. Acta, 388, 318-330 (1975).

17) Oelz, O., Seyberth, H. W., Knapp, Jr., H. R., Sweetman, B. J., and Oates, J. A., Effects of feeding ethyl-dihomogamma-linolenate on prostaglandin biosynthesis and platelet aggregation in the rabbit. Biochim. Biophys. Acta, 431, 268-277 (1976).

18) Knapp, H. R., Oelz, O., Whorton, A. R., and Oates, J. A.,
Effects of feeding ethyl-dihomo-gamma-linolenate on rabbit renomedullary lipid composition and prostaglandin production in vitro. Lipids, 13, 804-808 (1978).

19) Kawashima, H., Akimoto, K., Higashiyama, K., Fujikawa, S., and Shimizu, S., Industrial production of dihomo- $\gamma$-linolenic acid by $\Delta 5$ desaturase-defective mutant of mortierella alpine 1S-4 fungs. JAOCS, 77, 1135-1138 (2000).

20) Bieri, J., Stoewsand, G., Briggs, G., Phllis, R., Woodard, J., and Knapka, J., Report of the American Institute of Nutrition ad hoc committee on standards for nutritional studies. J. Nutr., 107, 1340-1348 (1977).

21) Folch, J., Lees, M., and Sloan Stanley, G. H., A simple method for the isolation and purification of total lipids from animal tissues. J. Biol. Chem., 226, 497-509 (1957).

22) Fujiyama-Fujiwara, Y., Ohmori, C., and Igarashi, O., Metabolism of gamma-linolenic acid in primary cultures of rat hepatocytes and in Hep G2 cells. J. Nutr. Sci. Vitaminol. (Tokyo), 35, 597-611 (1989).

23) Ozeki, Y., Sudo, T., Toga, K., Nagamura, Y., Ito, H., Ogawa, T., and Kimura, Y., Characterization of whole blood aggregation with a new type of aggregometer by a screen filtration pressure method. Thrombosis Research, 101, 65-72 (2001).

24) Ikeda, I., Sasaki, E., Yasunami, H., Nomiyama, S., Nakayama, M., Sugano, M., Imaizumi, K., and Yazawa, K., Digestion and lymphatic transport of eicosapentaenoic and docosahexaenoic acids given in the form of triacylglycerol, free acid and ethyl ester in rats. Biochim. Biophys. Acta, 1259, 297-304 (1995).

25) Bishop-Bailey, D., Pepper, J. R., Haddad, E. B., Newton, R., Larkin, S. W., and Mitchell, J. A., Induction of cyclooxygenase-2 in human saphenous vein and internal mammary artery. Arterioscler. Thromb. Vasc. Biol., 17, 1644-1648 (1997).

26) Matsumoto, H., Naraba, H., Murakami, M., Kudo, I., Yamaki, K., Ueno, A., and Ohishi, S., Concordant induction of prostaglandin E2 synthase with cyclooxygenase-2 leads to preferred production of prostaglandin E2 over thromboxane and prostaglandin D2 in lipopolysaccharide-stimulated rat peritoneal macrophages. Biochem. Biophys. Res. Commun., 230, 110-114 (1997).

27) Brock, T. G., McNish, R. W., and Peters-Golden, M., Arachidonic acid is preferentially metabolized by cyclooxygenase-2 to prostacyclin and prostaglandin E2. $J$. Biol. Chem., 274, 11660-11666 (1999).

28) Bennett, A., Tacca, M. D., Stamford, I. F., and Zebro, T., Prostaglandins from tumours of human large bowel. Br. J. Cancer, 35, 881-884 (1977).

29) Narisawa, T., Kusaka, H., Yamazaki, Y., Takahashi, M., Koyama, H., Koyama, K., Fukaura, Y., and Wakizaka, A., Relationship between blood plasma prostaglandin E2 and liver and lung metastases in colorectal cancer. Dis. Colon Rectum, 33, 840-845 (1990).

30) Jelinska, M., Tokarz, A., Oledzka, R., and Czorniuk-Sliwa, A., Effects of dietary linseed, evening primrose or fish oils on fatty acid and prostaglandin E2 contents in the rat livers and 7,12-dimethylbenz[a]anthracene-induced tumours. Biochim. Biophys. Acta, 1637, 193-199 (2003).

31) Hidalgo, G. E., Zhong, L., Doherty, D. E., and Hirschowitz, E. A., Plasma PGE-2 levels and altered 
cytokine profiles in adherent peripheral blood mononuclear cells in non-small cell lung cancer (NSCLC). Mol. Cancer, 1, 5 (2002).

32) Zurier, R. B., and Quagliata, F., Effect of prostaglandin E 1 on adjuvant arthritis. Nature, 234, 304-305 (1971).

33) Zurier, R. B., Sayadoff, D. M., Torrey, A. B., and Rothfield, N. F., Prostaglandin E treatment of NZB/ NZW mice. Arthritis Rheum., 20, 723-728 (1977).

34) Zurier, R. B., Prostaglandins, immune responses, and murine lupus. Arthritis Rheum., 25, 804-809 (1982).

35) Ziboh, V. A., The significance of polyunsaturated fatty acids in cutaneous biology. Lipids, 31 (Suppl), S249-253 (1996).

36) Levin, G., Duffin, K. L., Obukowicz, M. G., Hummert, S. L., Fujiwara, H., Needleman, P., and Raz, A., Differential metabolism of dihomo-gamma-linolenic acid and arachidonic acid by cyclo-oxygenase-1 and cyclo-oxygenase-2: implications for cellular synthesis of prostaglandin E1 and prostaglandin E2. Biochem. J., 365, 489-496 (2002).

37) Matsuzaka, T., Shimano, H., Yahagi, N., Amemiya-Kudo, M., Yoshikawa, T., Hasty, A. H., Tamura, Y., Osuga, J., Okazaki, H., Iizuka, Y., Takahashi, A., Sone, H., Gotoda, T., Ishibashi, S., and Yamada, N., Dual regulation of mouse delta(5)- and delta(6)-desaturase gene expression by SREBP-1 and PPARalpha. J. Lipid Res., 43, 107-114 (2002).

38) Tang, C., Cho, H. P., Nakamura, M. T., and Clarke, S. D., Regulation of human delta-6 desaturase gene transcription: identification of a functional direct repeat-1 element. J. Lipid Res., 44, 686-695 (2003).

39) de Urquiza, A. M., Liu, S., Sjoberg, M., Zetterstrom, R. H., Griffiths, W., Sjovall, J., and Perlmann, T., Docosahexaenoic acid, a ligand for the retinoid $\mathrm{X}$ receptor in mouse brain. Science, 290, 2140-2144 (2000).

40) Fan, Y. Y., Spencer, T. E., Wang, N., Moyer, M. P., and Chapkin, R. S., Chemopreventive n-3 fatty acids activate RXRalpha in colonocytes. Carcinogenesis, 24, 15411548 (2003).

41) Fujiwara, Y., Yokoyama, M., Sawada, R., Seyama, Y., Ishii, M., Tsutsumi, S., Aburatani, H., Hanaka, S., Itakura, H., and Matsumoto, A., Analysis of the comprehensive effects of polyunsaturated fatty acid on mRNA expression using a gene chip. J. Nutr. Sci.
Vitaminol. (Tokyo), 49, 125-132 (2003).

42) Berger, A., Mutch, D. M., German, J. B., and Roberts, M. A., Dietary effects of arachidonate-rich fungal oil and fish oil on murine hepatic and hippocampal gene expression. Lipids Health Dis., 1, 2 (2002).

43) Yoshikawa, T., Shimano, H., Yahagi, N., Ide, T., Amemiya-Kudo, M., Matsuzaka, T., Nakakuki, M., Tomita, S., Okazaki, H., Tamura, Y., Iizuka, Y., Ohashi, K., Takahashi, A., Sone, H., Osuga, J., Gotoda, T., Ishibashi, S., and Yamada, N., Polyunsaturated fatty acids suppress sterol regulatory element-binding protein $1 \mathrm{c}$ promoter activity by inhibition of liver $\mathrm{X}$ receptor (LXR) binding to LXR response elements. J. Biol. Chem., 277, 1705-1711 (2002).

44) Worgall, T. S., Sturley, S. L., Seo, T., Osborne, T. F., and Deckelbaum, R. J., Polyunsaturated fatty acids decrease expression of promoters with sterol regulatory elements by decreasing levels of mature sterol regulatory element-binding protein. J. Biol. Chem., 273, 2553725540 (1998).

45) Torra, I. P., Jamshidi, Y., Flavell, D. M., Fruchart, J. C., and Steals, B., Characterization of the human PPAR $\alpha$ promoter: identification of a functional nuclear receptor response element. Mol. Endocrinol., 16, 1013-1028 (2002).

46) Torra, I. P., Claudel, T., Duval, C., Kosykh, V., Fruchart, J. C., and Steals, B., Bile acid induces the expression of the human peroxisome proliferator-activated receptor $\alpha$ gene via activation of the farnesoid X receptor. Mol. Endocrinol., 17, 259-272 (2003).

47) Lemberger, T., Steals, B., Saladin, R., Desvergne, B., Auwerx, J., and Wahli, W., Regulation of the peroxisome proliferator-activated receptor $\alpha$ gene by glucocorticoids. J. Biol. Chem., 269, 24527-24530 (1994).

48) Hayhurst, G., Lee, Y. H., Lambert, G., Ward, J. M., and Gonzalez, F., Hepatocyte nuclear factor 4a (nuclear receptor 2A1) is essential for maintenance of hepatic gene expression and lipid homeostasis. Mol. Cell. Biol., 21, 1393-1403 (2001).

49) Rajas, F., Gautier, A., Bady, I., Montano, S., and Mithieux, G., Polyunsaturated fatty acyl coenzyme A suppresses the glucose-6-phosphatase promoter activity by modulating the DNA binding of hepatocyte nuclear

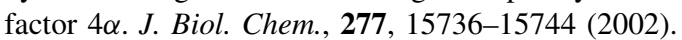

